\title{
BEHAVIOUR OF VARIOUS EXPERIMENTAL WALL FRAGMENTS EXPOSED TO REAL CLIMATE CONDITIONS - TEMPERATURE MEASUREMENT
}

\author{
DANIELA JURASOVA*, PETER JURAS \\ Univerzitna 8215/1, 01026 Zilina, Slovakia \\ *E-mail: daniela.jurasova@fstav.uniza.sk
}

\begin{abstract}
Main aim of this paper is to illustrate the experimental partial results of a study on various exterior wall fragments. The study was performed for selected wall fragments and time periods, with attention focused also on wall orientation (East and South) with identical layering and also on dynamic thermal parameters connected to the thermal comfort during summer and winter. Evaluation is done for real measured climate conditions in the area of experimental laboratory (exterior - University of Zilina) and interior conditions set according to the Slovak standard. For needs of the long-term experiment (since March 2017), temperature and relative humidity between layers are monitored. This paper deals specifically with the temperature measurement of selected days. For future publications also coupled heat-air-moisture transport analysis is intended. In this part of analysis, some extreme boundary conditions were selected and reviewed from the point of view of measured temperature inside the wall. Temperature peaks are characterized with respect to exposure to real atmospheric conditions.
\end{abstract}

Keywords: wall fragments, thermal insulation, temperature, relative humidity

\section{Introduction}

Many researchers deal with various wall fragments with advanced material forms and their characteristics, such as decrement factor and time lag [1], reduction of embodied energies and carbon [2], incorporation of transparent thermal insulations [3], vast analysis of thermal bridges in structures [4] and also with green roofs [5]. It is generally known that building envelope is one of the most important elements of the building. Not only the wall configuration but also orientation of the wall is crucial [6]. Main idea of our research is to monitor the wall parameters throughout all periods of the year continuously.

There is a wide variety of thermal analyses that can be used to characterize the wall thermal behaviour under indoor and outdoor conditions. For needs of this article, real outdoor boundary conditions were used. They were recorded by an experimental weather station. Experimental data correspond to samples at a laboratory scale [7]. Some suitable days were selected for evaluation. Characteristics of the wall are often studied under periodic boundary conditions of exterior climate influence and nearly constant interior air tem- perature of the laboratory room. Two factors are characteristic for the wall: the time lag and the decrement factor [1].

In literature, studies dealing with effect of wall orientation on them are in a limited number although there are many studies related to time lag and decrement factor [8, 9]. Micro-climate (exposure conditions - outdoor and indoor) and building physics together with material characteristics (regulation of thermal transmittance) are crucial for building envelopes. To achieve a better thermal performance of the wall, it is desirable to have a multi-layered wall comprising materials of different thermo-physical properties [10].

\section{Materials, boundary conditions and measuring methods}

Selected experimental wall fragments have identical layering and diverse orientation (Figs 1, 2).

Evaluation of summer weeks is important from the point of view of possible overheating, especially in case of walls exposed to real indoor and outdoor conditions. Wall configurations have from 3 to 8 layers (1 to 4 insulating layers). The samples represent an

This is an open-access article distributed under the terms of the Creative Commons Attribution-NonCommercial 4.0 International License (https://creativecommons.org/licenses/by-nc/4.0/), which permits unrestricted use, distribution, and reproduction in any medium for non-commercial purposes, provided the original author and source are credited, a link to the CC License is provided, and changes - if any - are indicated. 


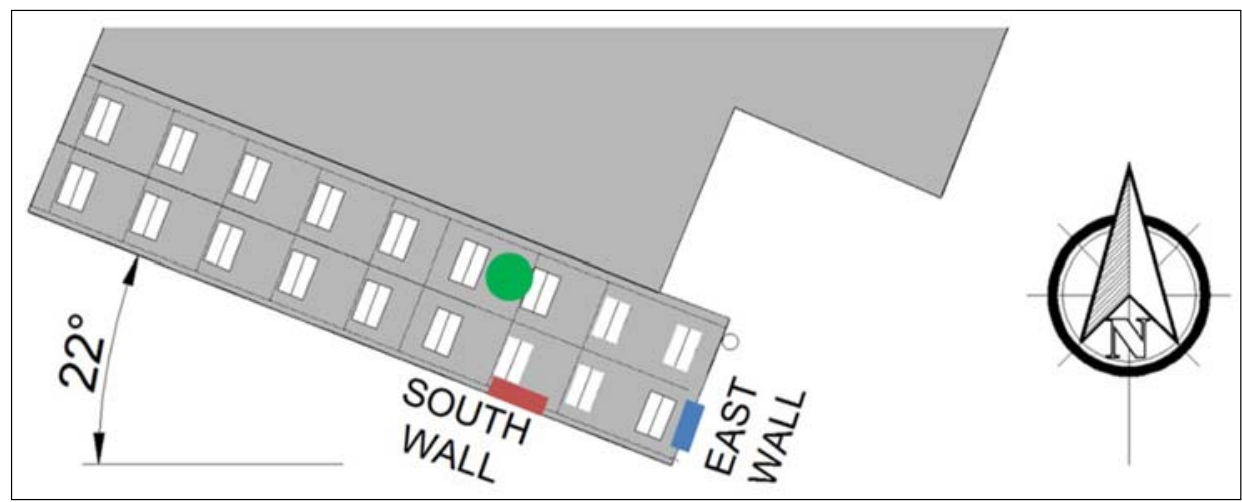

Fig. 1. Partial plan view of laboratories with marked sensor positions (south and east wall) and experimental weather station (marked in green)

improved building envelope suitable for zero energy buildings with $U$ value around $0.10 \mathrm{~W} /\left(\mathrm{m}^{2} \cdot \mathrm{K}\right)$. Values are better than requirements after 2021 according to the Slovak standard. Energy saving would be assigned by use of improved wall characteristics. Thermal properties of materials are received from producers as declared values. In the future, experimental measurement of real $\lambda$ values is planned together with recalculation and comparison of $U$ values.

Thermal characterization of wall fragments is main aim of this article to select the differences caused by wall orientation. We evaluate performance of selected structures, which might be used for wooden houses of the future. Information used for very first calculations and simulations were obtained from the technical support of producers and were taken as initial. The indoor conditions were set to oscillate around $20^{\circ} \mathrm{C}$. This was assigned by an AC unit [7].

\section{Wall fragment characteristics}

Experimental walls are oriented to South and East. Material characteristics are presented in Tables 1, 2.

Lightweight wall constructions become recently more popular in a way of possible reduction of energy consumption [11]. Both experimental walls consist of 5 vertical sections, detailed description is in [7]. Wood
Table 1. Wall fragment materials and properties (wall A, East and South)

\begin{tabular}{lcc}
\hline $\begin{array}{l}\text { Material (from outer to inner } \\
\text { surface) }\end{array}$ & $\begin{array}{c}\text { Thickness } \\
(\mathrm{mm})\end{array}$ & $\lambda=\mathrm{W} /(\mathrm{m} \cdot \mathrm{K})$ \\
\hline Wooden cladding & 28 & 0.18 \\
Ventilated air gap & 40 & - \\
Vapour barrier & 0.05 & 0.35 \\
Mineral fibre insulation & 100 & $0.036-0.039$ \\
Glass fibre insulation & 220 & 0.03 \\
Vapour barrier & 0.05 & 0.35 \\
OSB 3 board P + D & 12 & 0.13 \\
\hline
\end{tabular}

Table 2. Wall fragment materials and properties (wall B, East and South)

\begin{tabular}{lcc}
\hline $\begin{array}{l}\text { Material (from outer to inner } \\
\text { surface) }\end{array}$ & $\begin{array}{c}\text { Thickness } \\
(\mathrm{mm})\end{array}$ & $\lambda=\mathrm{W} /(\mathrm{m} \cdot \mathrm{K})$ \\
\hline Silicone coating & 2 & 0.86 \\
$\begin{array}{l}\text { Adhesive layer with grid } \\
\text { Sandwich board (grey poly- }\end{array}$ & 5 & 0.90 \\
styrene + & 120 & $0.033-0.034$ \\
Glass fibre based insulation & 220 & 0.03 \\
Hardened phenolic foam & 40 & 0.021 \\
OSB 3 board P + D & 12 & 0.13 \\
\hline
\end{tabular}

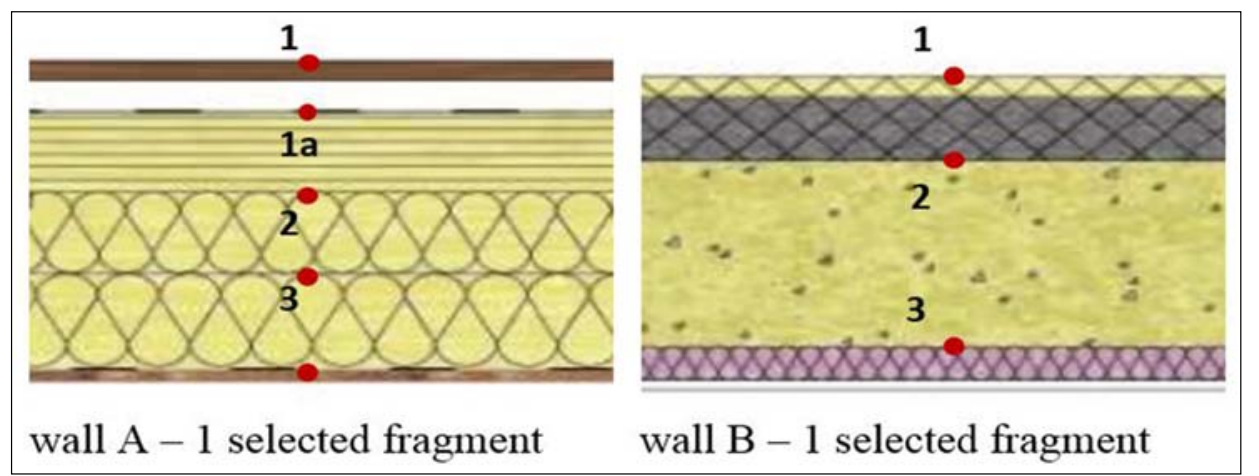

Fig. 2. Wall fragments selected for comparison - individual sensor positions, east (E) and south (S) orientation 


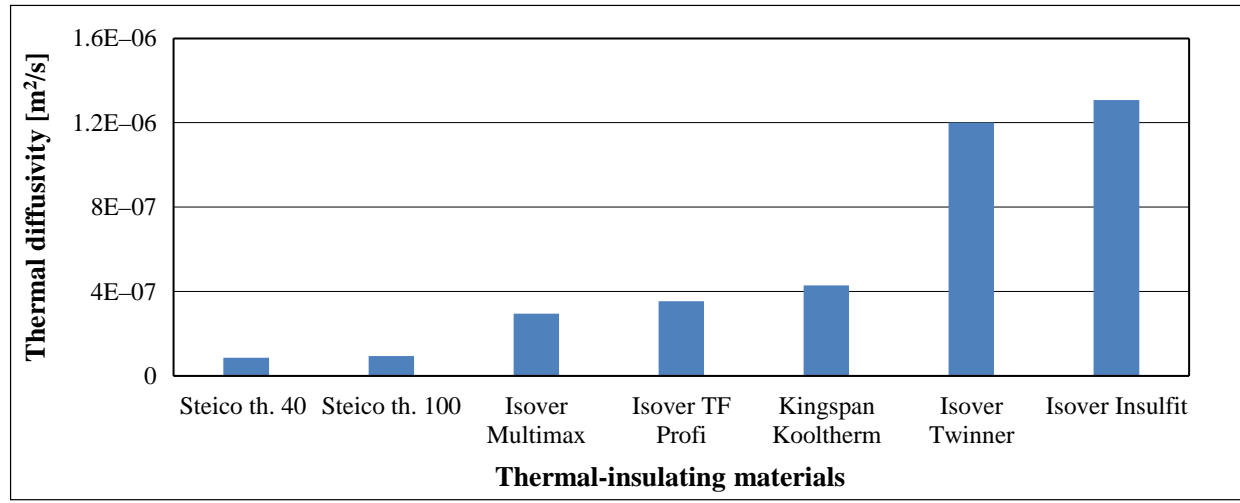

Fig. 3. Used thermal-insulating materials according to the coefficient of thermal diffusivity

in framing of the wall is identified as timber. This type of structure enables variability of material changes in the future - e.g. change of thermal insulation according to the future Standards. In order to evaluate various structures, 8 different fragments were built into two experimental walls - the east and the south one. Individual fragments differ from each other by use of main thermal insulation, technology of realization, exterior finish and surface color. Between bordering layers, temperature and relative humidity sensors are placed in three high levels (bottom, middle and top). The data are collected since March 2017 in a 15-minute time step. They will also be used in the future to evaluate the fragments in various possible ways, together with computer simulations. For evaluation in this paper, 4 wall fragments were selected.

If it is needed to have a good thermal inertia, the material has to have the low value of thermal diffusivity (Fig. 3).

Temperature stability describes constancy of the temperature by time-variable boundary conditions, mainly the exterior ones.

\section{Results and discussion}

For the comparison of two wall types and influence of the wall orientation (Fig. 1), two time periods were selected. Three cold days (Fig. 3) combine very low night temperatures and a lot of sunshine during the day, which induces surface temperatures above the freezing point.

First point of comparison - exterior surface shows the difference between temperatures on the ventilated wooden cladding and on the surface of thermal insulation - this difference is about $10^{\circ} \mathrm{C}$ during the time in which the wall gets the direct solar radiation (the first and third day). Another 8 and $12{ }^{\circ} \mathrm{C}$ is the difference on the surface of this cladding between east and south oriented wall. Because of the ventilated air gap, the cladding is more heated than the surface of the wall $\mathrm{B}$ with plaster, the difference is about $4{ }^{\circ} \mathrm{C}$. Surface of the wall B shows similar difference between the east and south orientation, only the values are lower. The outcome is that in winter, the surface below the ventilated air gap has reached lower values

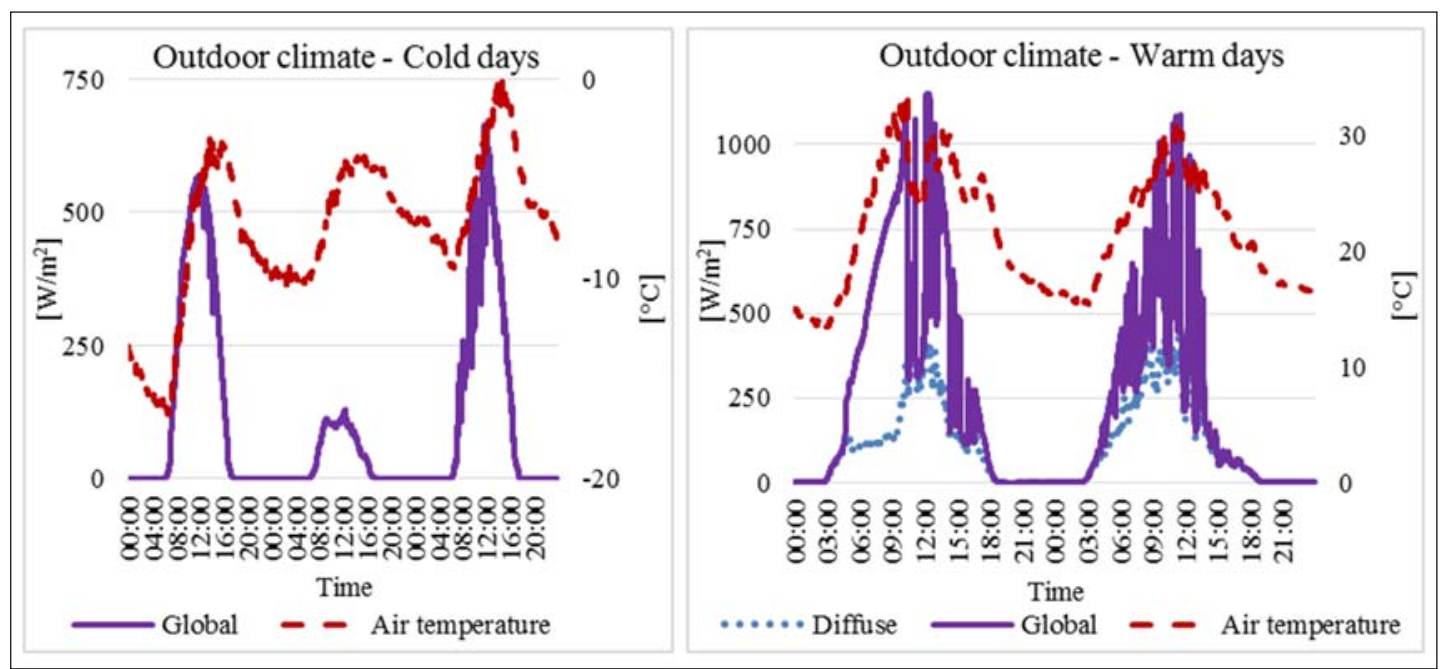

Fig. 4. Measured hourly outdoor air temperature and global horizontal radiation, cold days 1-3 March 2018 (left), warm days 5-6 June 2018 (right) 
of temperature than the surface of coating. The ventilation of air gap has its function, but in winter it does not increase the heat gains during the sunny days. During the nights, there is very small difference between the temperatures.

Position 2 shows again the similar difference between south and east orientation for both wall types. Temperature peaks are shifted as the result of sun movements on the sky and the phase shift influenced by the materials. These two have similar specific heat capacity but different density. This fact influenced the shape of the course peaks. Position 3 is not comparable directly between wall A and B, because of the different sensor position depths in the wall structure. There are small differences between the courses during the night but small peaks of the

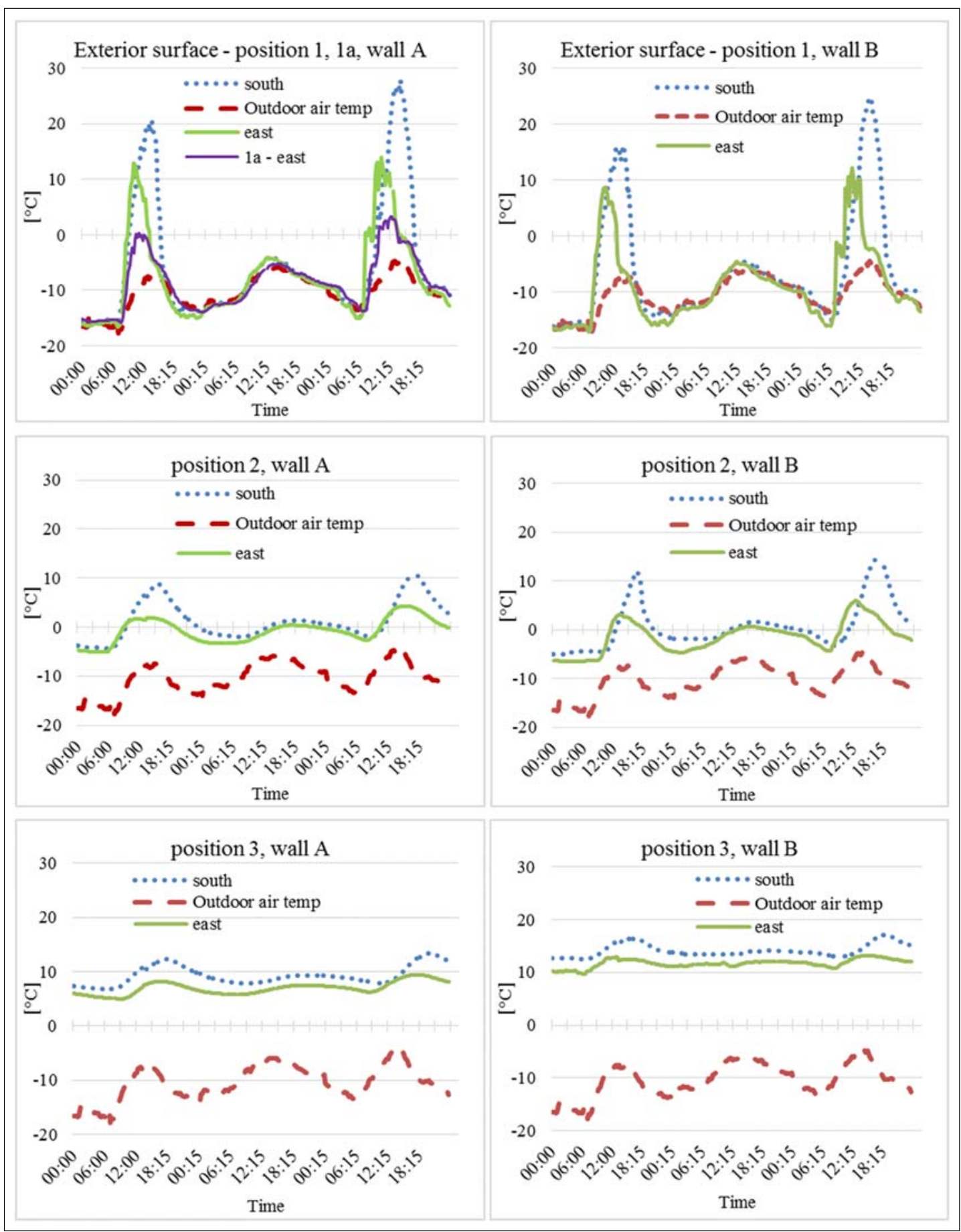

Fig. 5. Temperature courses at selected positions in the wall A (left) and wall B (right) during cold days (1-3 March 2018), Zilina 
south oriented wall over the east oriented wall are still visible.

For the comparison of warm days, two days were chosen, in similar principle as for the winter, one day was sunny and the second one was partly cloudy (Fig. 6).

The official summer period begins on 21 June, but the warm half-year lasts from April to September and the cold half-year includes a period from October to March. Evaluated days were selected from cold and warm half-year. The period 1-3 March represents the cold half-year and 5-6 June represents the warm halfyear.
There is a specific air temperature drop in the first warm day at 10:24 (UTC time), which is caused by the small rain event. This influenced also the surface temperature. Courses for the east oriented wall reached their peaks and the south orientation showed increase when this sudden event occurred and the temperature dropped quickly, air temperature $6{ }^{\circ} \mathrm{C}$ and south façade surface up to $11^{\circ} \mathrm{C}$. After the rain event, the temperature rose again, but the south oriented wall did not reach the peaks like the east oriented wall did. The difference for temperatures of the wall with ventilated air gap A are about $11{ }^{\circ} \mathrm{C}$ (surface of cladding and surface of the wall itself). So

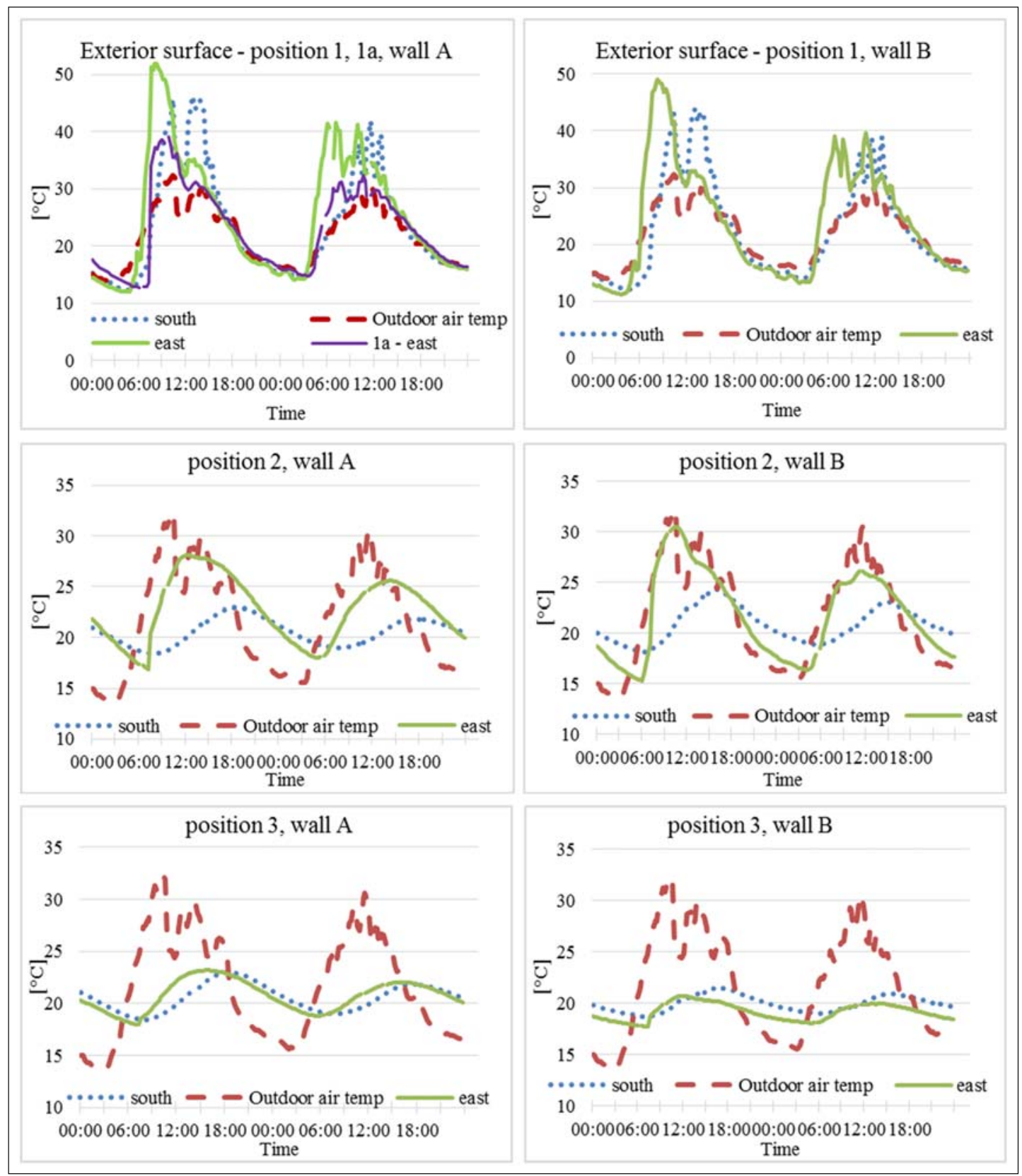

Fig. 6. Temperature courses at selected positions in the wall A (left) and wall B (right) during warm days (5-6 June 2018), Zilina 


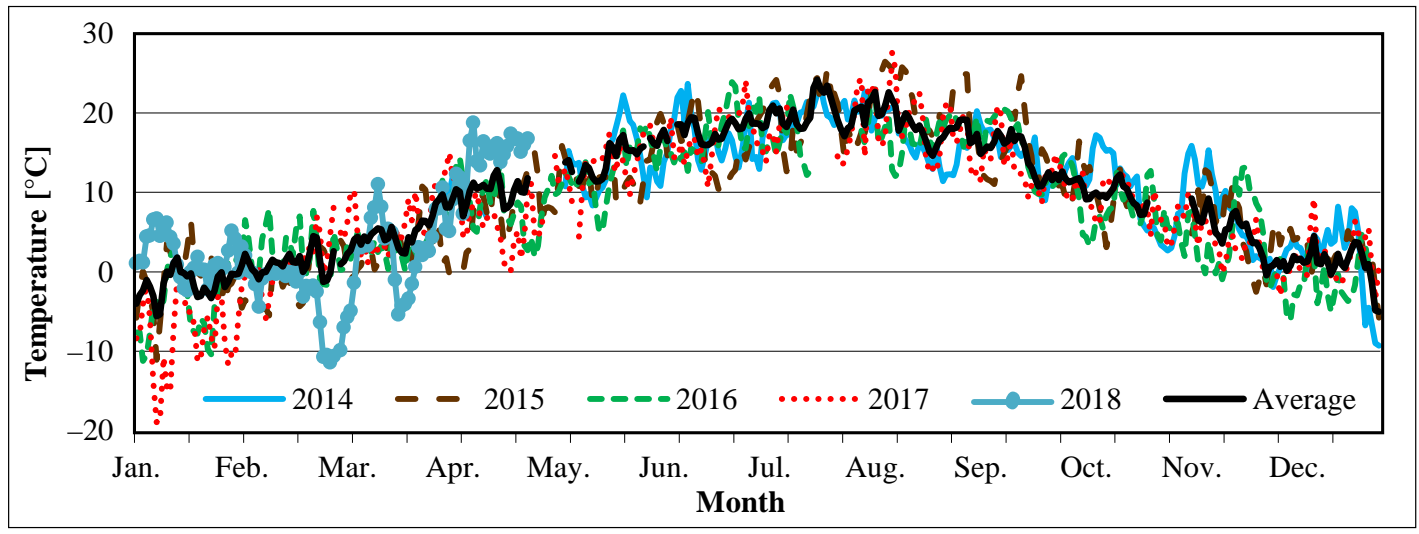

Fig. 7. Outdoor boundary conditions measured since May 2014

the ventilated air gap reduces the surface temperature significantly. This has a positive effect to avoid the overheating of the indoor environment. Caused by the different colours of the cladding and coating on the experimental wall $B$, the wall $B$ has lower surface temperature at about $3{ }^{\circ} \mathrm{C}$, which still leaves an advantage for the composition with ventilated air gap wall A. Position 2 shows different temperature peaks, higher for the east orientation caused by the fact that the temperature on the east oriented façade was higher on the selected days. The peak shift is similar to orientation. There is still up to $5^{\circ} \mathrm{C}$ in advantage of the wall fragment with ventilated air gap as the outcome of lower surface temperature. This is almost the same for both orientations. Position 3 shows small amplitudes in the courses. The difference between the two wall orientations is visible. Again, these two positions cannot be compared directly because of their slightly different location.

For future building simulations, various files for outdoor boundary conditions will be applied according to the point of view of evaluation (Fig. 7). Continuous measurement is assigned by own experimental weather station located near the laboratory (Fig. 1).

Figure 7 graphically shows the change of external boundary conditions during last years (from year to year). It should give only an overview of temperature changes over time. Presented time period is recorded since May 2014 to March 2018. During last years it is to observe that the climate seems like having only winter and summer part (without spring and autumn look). Visible is also the fact that the year 2018 shows winter extremes in February and the year 2017 represents more extreme temperatures in January. January 2018 shows also extremes, not freeze but temperatures above zero. According to the climate variability, it would be possible to use various variants of reference files for building simulations for real wall structures and to compare results to the real experimental laboratory measurement.

\section{Conclusion}

As it is well known, thermal loss (energy loss) gets decreased by increasing the insulation thickness and characteristics of building walls [1]. Main aim of this study was application of common methods for wall thermal analysis, done for two identical couples of wall fragments with different orientation. To the outer wall surface, real measured boundary conditions were applied. External and internal surface temperatures of the wall strongly influence time lag and decrement factor as two crucial thermal performance parameters. For that reason, outdoor and indoor temperature is of great interest to investigate. Various building materials were used in selected wall fragments. Complete continuous recordings of all wall parameters are at our disposal for a time period of 1 year, beginning in March 2017. Recording time step for experimental walls is variable. Usually it is set to a 15-minute recording interval. Monitoring of external boundary conditions is also variable. Mostly it is adapted to the needs of software for building simulation (e.g., WUFI). Both evaluated wall fragments (A and B) showed differences between coatings (material point of view) and also between orientations. Evaluation of building materials according to the thermal diffusivity factor gives a quick idea of real behaviour of various thermal-insulating materials exposed to temperature changes. Only individual materials should be compared, not the structures, because it is not possible to take into account the position of individual structural layers.

\section{Acknowledgements}

This article was created with support of the grant project VEGA No. 1/0683/16 and with assistance of Slovak Hydrometeorological Institute in Bratislava (SHMI). 


\section{References}

[1] Ozbalta T. G., Ozbalta N. (2010), The effects of insulation location and thermos-physical properties of various external wall materials on decrement factor and time lag. Scientific Research and Essays, 5(23), 3646-3659.

[2] Lupisek A., et al. (2015), Design Strategies for Low Embodied Carbon and Low Embodied Energy Buildings: Principles and Examples. Energy Procedia 83. Elsevier, pp. 147-156.

[3] Cekon M., Slavik R., Zach J. (2017), Experimental Analysis of Transparent Insulation Based on Polycarbonate Multi-Wall Systems: Thermal and Optical Performance. Energy Procedia 132. Elsevier, pp. 502-507.

[4] Alhawari A., Mukhopadhayaya P. (2018), Thermal bridges in building envelopes - an overview of impacts and solutions. Int. Rev. Appl. Sci. Eng., 9, 31-40.

[5] Vertal M., et al. (2018), Hygrothermal initial condition for simulation process of green building construction. Energy and Buildings, 167, 166-176.

[6] Larsen S. F., Filipin C., Lesino G. (2009), Thermal behaviour of building walls in summer: Comparison of availa- ble analytical methods and experimental results for a case study. Building Simulation, 2, 3-18.

[7] Staffenova D., et al. (2017), Intention, principle and aims of the experimental pavilion research of building envelopes including windows for wooden buildings. Civil and Environmental Engineering, 13, 42-51.

[8] Ozel M., Ozel C. (2012), Effects of wall orientation and thermal insulation on time lag and decrement factor. HEFAT2012. Malta.

[9] Kontoleon K. J., Bikas D. K. (2005), Thermal mass vs. thermal response factors: determining optimal geometrical properties and envelope assemblies of building materials. Passive and Low Energy Cooling for the Built Environment. Greece.

[10] Balaji N. C., et al. (2013), Thermal Performance of the Building Walls. 1st IBPSA Italy Conference.

[11] Radon J., et al. (2017), Experimental and theoretical study on hygrothermal long-term performance of outer assemblies in lightweight passive house. Journal of Building Physics, 299-320. 